\section{Genome Sequence Resource for Stemphylium vesicarium, Causing Brown Spot Disease of Pear}

\author{
Katia Gazzetti, ${ }^{1}$ Elena L. Diaconu, ${ }^{2}$ Irene M. Nanni, ${ }^{1}$ Alessandro Ciriani, ${ }^{1}$ and Marina Collina ${ }^{1 \dagger}$ \\ ${ }^{1}$ Department of Agricultural and Food Sciences, University of Bologna, Viale G. Fanin, 42, 40127 \\ Bologna, Italy \\ ${ }^{2}$ Bio-Fab Research srl, Via Mario Beltrami, 5, 00135 Roma, Italy
}

\section{Keywords}

allergy, BSP, fungicides, NGS

\begin{abstract}
Stemphylium vesicarium is the causal agent of several plant diseases as well brown spot of pear (BSP), which is one of the most economically important fungal diseases in European pearproduction areas. In addition to the relevance of the economic impact, conidia spread widely from plant material infected by the pathogen can trigger respiratory allergy. Here, we report the first genome of a $S$. vesicarium strain, 173-1a13FI1M3, isolated from pear and sensitive to the mostly used fungicide classes currently authorized in Europe against BSP. The availability of this draft genome could represent a first important step in understanding the physiology and the infection mechanism of the pathogen. Furthermore, this contribution could be fundamental in order to design more effective and sustainable strategies to control the disease.
\end{abstract}

\section{Genome Announcement}

Stemphylium vesicarium (Wallr.) E. G. Simmons belongs to the class Dothideomycetes, order Pleosporales, and its teleomorph is Pleorospora allii (Rabenh.) Ces. \& De Not (Simmons 1969). This fungus can cause disease of noncrop plants, herbaceous crops, and fruit trees (Falloon et al. 1987; Lamprecht et al. 1984; Rossi et al. 2005; Suheri and Price 2000). Brown spot of pear (BSP), caused by S. vesicarium, is the most economically relevant fungal disease for many varieties of pear in Italy and in other European countries, because it may cause loss of production up to $100 \%$ (Llorente et al. 2012). During the infection process, the germinating conidia produce two host-specific toxins, SV-I and II (Singh et al. 1999), able to induce ultrastructural changes in the plasma membrane of susceptible leaf cells (Singh et al. 2000). Throughout the season, both leaves and fruit can be damaged and, thus, many fungicide applications are required from petal fall to fruit ripening to protect pear orchards (Alberoni et al. 2010b). The fungus has been shown to be capable of developing field resistance toward key products such as dicarboximides, fludioxonil (Alberoni et al. 2005; Gazzetti et al. 2017) and strobilurins (Alberoni et al. 2010a). Furthermore, it is known that conidia of Stemphylium spp. can induce respiratory allergy (Sáenz-de-Santamaría et al. 2006; Weber 2015). Therefore, understanding the $S$. vesicarium genome sequence is a fundamental step toward increasing our knowledge about this important organism, both for plant protection and human health.

$S$. vesicarium strain 173-1a13FI1M3 was grown from a single conidium, isolated from a culture originally sampled on 2 August 2013 from leaves of pear affected by BSP, belonging to the highly BSP susceptible cultivar Abate Fétel collected in an untreated orchard located in

${ }^{\dagger}$ Corresponding author: M. Collina; marina.collina@unibo.it

The author(s) declare no conflict of interest.

Accepted for publication 19 March 2019.

(C) 2019 The American Phytopathological Society 
Table 1. Core metrics of the Stemphylium vesicarium 173-1a13FI1M3 genome draft and average nucleotide identity (ANI) comparison between S. vesicarium 173-1a13FI1M3 and other plant pathogens

\begin{tabular}{|c|c|c|c|c|c|}
\hline \multicolumn{2}{|l|}{ Genome features } & \multicolumn{4}{|c|}{ ANI comparison } \\
\hline Core metrics, pathogens & Numbers & Strain & Accession $^{a}$ & NUCmer ${ }^{b}$ & Blast $^{c}$ \\
\hline \multicolumn{6}{|l|}{ Metrics } \\
\hline Number of contigs ( $\geq 0 \mathrm{bp}$ ) & 1,127 & $\ldots$ & $\ldots$ & $\ldots$ & $\ldots$ \\
\hline Number of contigs ( $\geq 25,000 \mathrm{bp})$ & 278 & $\ldots$ & $\ldots$ & $\ldots$ & $\ldots$ \\
\hline N50 (bp) & 167,978 & $\ldots$ & $\ldots$ & $\ldots$ & $\ldots$ \\
\hline L50 (bp) & 63 & $\ldots$ & $\ldots$ & $\ldots$ & $\ldots$ \\
\hline Largest contig (bp) & 974,405 & $\ldots$ & $\ldots$ & $\ldots$ & $\ldots$ \\
\hline Assembly length (bp) & $38,664,579$ & $\ldots$ & $\ldots$ & $\ldots$ & $\ldots$ \\
\hline Genome coverage & $60 x$ & $\ldots$ & $\ldots$ & $\ldots$ & $\ldots$ \\
\hline CG content (\%) & 50.72 & $\ldots$ & $\ldots$ & $\ldots$ & $\ldots$ \\
\hline BUSCO completeness (\%) & 96 & $\cdots$ & $\cdots$ & $\cdots$ & $\cdots$ \\
\hline Number of predicted genes & 12,309 & $\ldots$ & $\ldots$ & $\ldots$ & $\ldots$ \\
\hline Number of coding sequences ${ }^{d}$ & 12,230 & & & & \\
\hline \multicolumn{6}{|l|}{ Pathogens } \\
\hline Stemphylium vesicarium & $\ldots$ & 173-1a13FI1M3 & QXCR00000000 & 1.000 & 1.000 \\
\hline Tuber melanosporum & $\ldots$ & Mel28 & ASM15164v1 & 0.0001 & 0.003 \\
\hline Botrytis cinerea & $\ldots$ & B05.10 & ASM14353v4 & 0.0006 & 0.017 \\
\hline Pyrenophora teres & $\ldots$ & W1-1 & ОСТН01000000 & 0.0834 & 0.330 \\
\hline Alternaria alternata & $\ldots$ & SRC1lrK2f & LXPP01000000 & 0.1195 & 0.608 \\
\hline Stemphylium lycopersici & $\ldots$ & CIDEFI 216 & LGLR01000000 & 0.7374 & 0.774 \\
\hline
\end{tabular}

a Accession number.

b ANI-NUCmer values.

c ANI-Blast values.

d Number of predicted complete coding sequences.

Altedo (Emilia-Romagna region, Italy). This strain is deposited at the CBS-KNAW culture collection (accession number CBS 145331; Westerdijk Fungal Biodiversity Institute, Utrecht, The Netherlands). The deposited culture is sensitive to dicarboximides, fludioxonil, strobilurins, and succinate dehydrogenase inhibitor (SDHI) fungicides, as verified by biological assays conducted as described by Alberoni et al. (2005, 2010a,b) and Ciriani et al. (2016). The sensitivity of strain 173-1a13FI1M3 to these fungicides was confirmed by Sanger sequencing. Indeed, wild-type alleles were obtained by sequencing of SvHK1 and the $S$. vesicarium orthologous of $c y t b$ and of the SdhB, -C, and -D subunit encoding genes, involved in the resistance toward dicarboximides and fludioxonil (Alberoni et al. 2010b), strobilurins (Alberoni et al. 2010a), and SDHI fungicides (unpublished data), respectively.

The genomic DNA of $S$. vesicarium strain 173-1a13FI1M3 was isolated from fresh mycelium, following a cetyltrimethylammonium bromide-based method (Alberoni et al. 2010a), with modifications: nucleic acids were separated by chloroform/isoamyl alcohol (24:1) and precipitated in isopropanol (1V) and $3 \mathrm{M} \mathrm{NaAc}, \mathrm{pH} 5.2(0,1 \mathrm{~V})$. The pellet was dissolved in $10 \mathrm{mM}$ Tris- $\mathrm{HCl}, \mathrm{pH}$ 8, and yield, purity, and integrity of DNA were accurately determined by gel electrophoresis and by both spectrophotometric and fluorometric quantification. Shotgun libraries were prepared following the manufacturer's recommendation for the TrueSeq DNA Sample Preparation Kit, and Illumina MiSeq v3 was used to perform the $2 \times$ 300-bp paired-end sequencing, producing $2 \times 23,806,218$ paired-end sequences $(2 \times 6.45$ $\mathrm{Gb})$. Library preparation and sequencing was done by BMR Genomics (Padua, Italy). The obtained raw sequences were cleaned up and filtered in order to discard reads with average quality of phred score lower than 30 by Trimmomatic (Bolger et al. 2014). The genome was de novo assembled in 1,127 contigs by SPAdes 3.6 (Bankevich et al. 2012). QUAST was used to assess assembly quality (Gurevich et al. 2013). Total assembly length was $38.66 \mathrm{Mb}$ (genome coverage 60x), similar to the genome assembly size of $S$. lycopersici (Franco et al. 2015 ), with a GC content of $50.72 \%$ and a N50 value of 167,978 . The longest contig consisted of $974,405 \mathrm{bp}$.

Average nucleotide identity (ANI) is proposed as the appropriate in silico substitute for DNA-DNA hybridization and, thus, is useful for delineating species boundaries (Richter and Rosselló-Móra 2009). ANI was calculated between the S. vesicarium $173^{1 \mathrm{a}}{ }_{13 \mathrm{~F} / 1 \mathrm{M} 3}$ genome and other filamentous plant pathogens, some of which belonging to the order Pleosporales. In order to achieve a wider vision of overall genomes relatedness, the ANI calculation was made by both MUMmer2 NUCmer (Delcher et al. 2002) and NCBI BLAST (Goris et al. 2007), based 
on two different algorithm structures. Tuber melanosporum was used as the outgroup. Obtained ANI values are reported in Table 1 together with the core metrics of the S. vesicarium $173^{1 \mathrm{a}}{ }_{13 \mathrm{FI} 1 \mathrm{M} 3}$ genome.

For de novo gene prediction, PASA (Haas et al. 2003) was used as the ab initio gene finding for AUGUSTUS 3.2.1 (Stanke and Morgenstern 2005) and GENEMARK (Borodovsky and Ekisheva 2006). Results showed 12,309 genes, of which 12,230 were complete coding sequences that covered $44.6 \%$ of the genome sequence. Mean gene length was $1,585 \mathrm{bp}$ and the mean number of exons per gene was 3 . The prediction was analyzed by BUSCO v12 (Simão et al. 2015) in order to evaluate the completeness with a set of common fungal singlecopy orthologs, estimating the genome to be $96 \%$ complete. A primary functional annotation was made using the hierarchical orthology framework eggNOG 4.5 (Huerta-Cepas et al. 2016) providing the annotations of orthologous groups, as well gene ontology (GO) terms, KEGG pathways, and SMART/Pfam domains for each group. Combined prediction of transmembrane topology and signal peptide was carried out by Phobius (Käll et al. 2004). Genome sequence was analyzed by AntiSMASH 3.0 fungal version (Weber et al. 2015), for the automatic genomic identification and analysis of biosynthetic gene clusters.

Overall, the annotation analysis predicted 40 genes described by the $\mathrm{GO}$ term defining involvement in pathogenesis (GO 0009405). Searching the PHI-base for possible orthologs of pathogenicity genes from other plant pathogens, at default setting, identified three matches involved in appressorial development and function: the orthologs of MoERR1 (Goh et al. 2017), MGG_04128 (Jeon et al. 2007), and the tetraspanine CIPLS1 (VeneaultFourrey et al. 2005). In total, 521 genes were predicted as coding for carbohydrate-active enzymes; 77 of them are defined as components located in an extracellular region (GO 0005576) and putatively code for glycoside hydrolase $(\mathrm{GH})$, auxiliary activity, polysaccharide lyase, and carbohydrate esterase enzymes families, all classes that are considered cell-wall-degrading enzymes and may have a role in plant infection (Hou et al. 2016; Walton 1994). Among members of the GH11 family, an orthologous gene for $x y n 11 A$ was predicted, an effector of the necrotrophic fungus Botrytis cinerea (Noda et al. 2010). The annotation process classified 553 predicted genes as involved in secondary metabolism. These genes could be investigated for a possible role in several biosynthetic pathways, with particular interest directed to those leading to the production of secondary metabolites related to fungal pathogenesis and virulence such as the SV-I and II HSTs that have been little studied to date. In total, 444 predicted genes have functions associated with signal transduction mechanisms and, in particular, 4 are predicted to encode for histidine kinases and could be candidate targets for fungicides inhibiting signaling in osmoregulation pathway (Alberoni et al. 2010b). Moreover, the annotation was able to detect the orthologs of alt a 1 major and alt a 7 minor allergens (Gabriel et al. 2016), probably involved in respiratory allergies triggered by Stemphylium conidia (Agarwal et al. 1982; Sáenz-deSantamaría et al. 2006).

The draft genome presented here is the first available genome sequence of $S$. vesicarium, and only the second of the Stemphylium genus. Knowledge of this genome sequence opens a new scenario in the investigation of fungal lifestyle, epidemiology, and molecular plantpathogen interaction. The sequence of $S$. vesicarium strain 173-1a13Fl1M3 could be used in comparative studies and, as reference genome, to discover mutations in fungicide target genes of resistant strains. Therefore, this resource could improve the possibility of an integrated control of BSP and of other plant infections. Moreover, the new data available could make it possible to investigate $S$. vesicarium as a potential allergenic fungus in humans. The genome sequence has been deposited in the GenBank under accession number QXCR00000000 (BioProject: PRJNA470620, BioSample: SAMN09098503).

\section{Acknowledgments}

We thank G. Malacrida for the helpful suggestions concerning DNA extraction process. 


\section{Literature Cited}

Agarwal, M. K., Jones, R. T., and Yunginger, J. W. 1982. Shared allergenic and antigenic determinants in Alternaria and Stemphylium extracts. J. Allergy Clin. Immunol. 70:437-444.

Alberoni, G., Cavallini, D., Collina, M., and Brunelli, A. 2010a. Characterization of the first Stemphylium vesicarium isolates resistant to strobilurins in Italian pear orchards. Eur. J. Plant Pathol. 126:453-457.

Alberoni, G., Collina, M., Cavallini, D., and Brunelli, A. 2010b. Field strains of Stemphylium vesicarium with a resistance to dicarboximide fungicides correlated with changes in a two-component histidine kinase. Eur. J. Plant Pathol. 128: 171-184.

Alberoni, G., Collina, M., Pancaldi, D., and Brunelli, A. 2005. Resistance to dicarboximide fungicides in Stemphylium vesicarium of Italian pear orchards. Eur. J. Plant Pathol. 113:211-219.

Bankevich, A., Nurk, S., Antipov, D., Gurevich, A. A., Dvorkin, M., Kulikov, A. S., Lesin, V. M., Nikolenko, S. I., Pham, S., Prjibelski, A. D., Pyshkin, A. V., Sirotkin, A. V., Vyahhi, N., Tesler, G., Alekseyev, M. A., and Pevzner, P. A. 2012. SPAdes: A new genome assembly algorithm and its applications to single-cell sequencing. J. Comput. Biol. 19:455-477.

Bolger, A. M., Lohse, M., and Usadel, B. 2014. Trimmomatic: A flexible trimmer for Illumina sequence data. Bioinformatics 30:2114-2120.

Borodovsky, M., and Ekisheva, S. 2006. Problems and Solutions in Biological Sequence Analysis. Cambridge University Press. Cambridge.

Ciriani, A., Gazzetti, K., and Collina, M. 2016. Baseline sensitivity of Stemphylium vesicarium of pear to SDHls and fluazinam. J. Plant Pathol. 98:S41.

Delcher, A. L., Phillippy, A., Carlton, J., and Salzberg, S. L. 2002. Fast algorithms for large-scale genome alignment and comparison. Nucleic Acids Res. 30: 2478-2483.

Falloon, P. G., Falloon, L. M., and Grogan, R. G. 1987. Etiology and epidemiology of Stemphylium leaf spot and purple spot of asparagus in California. Phytopathology 77:407-413.

Franco, M. E. E., López, S., Medina, R., Saparrat, M. C. N., and Balatti, P. 2015. Draft Genome Sequence and Gene Annotation of Stemphylium lycopersici Strain CIDEFI-216. Genome Announc. 3:e01069-e15.

Gabriel, M. F., Postigo, I., Tomaz, C. T., and Martínez, J. 2016. Alternaria alternata allergens: Markers of exposure, phylogeny and risk of fungi-induced respiratory allergy. Environ. Int. 89-90:71-80.

Gazzetti, K., Ciriani, A., Brunelli, A., and Collina, M. 2017. Role of site-specific allele replacement into SvHK1 locus in the study of $S$. vesicarium resistance to dicarboximide and phenylpyrrole fungicides. Pages 95-100 in: Modern Fungicides and Antifungal Compounds VIII. H. B. Deising, B. Fraaije, A. Mehl, E. C. Oerke, H. Sierotski, and G. Stammler, eds. DPG Verlag, Braunschweig, Germany.

Goh, J., Jeon, J., and Lee, Y. H. 2017. ER retention receptor, MoERR1 is required for fungal development and pathogenicity in the rice blast fungus, Magnaporthe oryzae. Sci. Rep. 7: Article 1259.

Goris, J., Konstantinidis, K. T., Klappenbach, J. A., Coenye, T., Vandamme, P., and Tiedje, J. M. 2007. DNA-DNA hybridization values and their relationship to whole-genome sequence similarities. Int. J. Syst. Evol. Microbiol. 57:81-91.

Gurevich, A., Saveliev, V., Vyahhi, N., and Tesler, G. 2013. QUAST: Quality assessment tool for genome assemblies. Bioinformatics 29:1072-1075.

Haas, B. J., Delcher, A. L., Mount, S. M., Wortman, J. R., Smith, R. K., Jr., Hannick, L. I., Maiti, R., Ronning, C. M., Rusch, D. B., Town, C. D., Salzberg, S. L., and White, O. 2003. Improving the Arabidopsis genome annotation using maximal transcript alignment assemblies. Nucleic Acids Res. 31:5654-5666.

Hou, Y., Ma, X., Wan, W., Long, N., Zhang, J., Tan, Y., Duan, S., Zeng, Y., and Dong, Y. 2016. Comparative genomics of pathogens causing brown spot disease of tobacco: Alternaria longipes and Alternaria alternata. PLoS One 11:e0155258.
Huerta-Cepas, J., Szklarczyk, D., Forslund, K., Cook, H., Heller, D., Walter, M. C., Rattei, T., Mende, D. R., Sunagawa, S., Kuhn, M., Jensen, L. J., von Mering, C., and Bork, P. 2016. eggNOG 4.5: A hierarchical orthology framework with improved functional annotations for eukaryotic, prokaryotic and viral sequences. Nucleic Acids Res. 44:D286-D293.

Jeon, J., Park, S. Y., Chi, M. H., Choi, J., Park, J., Rho, H. S., Kim, S., Goh, J., Yoo, S., Choi, J., Park, J. Y., Yi, M., Yang, S., Kwon, M. J., Han, S. S., Kim, B. R., Khang, C. H., Park, B., Lim, S. E., Jung, K., Kong, S., Karunakaran, M., Oh, H. S., Kim, H., Kim, S., Park, J., Kang, S., Choi, W. B., Kang, S., and Lee, Y. H. 2007. Genome-wide functional analysis of pathogenicity genes in the rice blast fungus. Nat. Genet. 39:561-565.

Käll, L., Krogh, A., and Sonnhammer, E. L. L. 2004. A combined transmembrane topology and signal peptide prediction method. J. Mol. Biol. 338:1027-1036.

Lamprecht, S. C., Baxter, A., and Thompson, A. H. 1984. Stemphylium vesicarium on Medicago spp. in South Africa. Phytophylactica 16:73-75.

Llorente, I., Moragrega, C., Ruz, L., and Montesinos, E. 2012. An update on control of brown spot of pear. Trees (Heidelberg, Ger.) 26:239-245.

Noda, J., Brito, N., and González, C. 2010. The Botrytis cinerea xylanase Xyn11A contributes to virulence with its necrotizing activity, not with its catalytic activity. BMC Plant Biol. 10:38.

Richter, M., and Rosselló-Móra, R. 2009. Shifting the genomic gold standard for the prokaryotic species definition. Proc. Natl. Acad. Sci. U.S.A. 106:19126-19131.

Rossi, V., Pattori, E., Giosué, S., and Bugiani, R. 2005. Growth and sporulation of Stemphylium vesicarium, the causal agent of brown spot of pear, on herb plants of orchard lawns. Eur. J. Plant Pathol. 111:361-370.

Sáenz-de-Santamaría, M., Postigo, I., Gutierrez-Rodríguez, A., Cardona, G., Guisantes, J. A., Asturias, J., and Martínez, J. 2006. The major allergen of Alternaria alternata (Alt a 1) is expressed in other members of the Pleosporaceae family. Mycoses 49:91-95.

Simão, F. A., Waterhouse, R. M., loannidis, P., Kriventseva, E. V., and Zdobnov, E. M. 2015. BUSCO: Assessing genome assembly and annotation completeness with single-copy orthologs. Bioinformatics 31:3210-3212.

Simmons, E. G. 1969. Perfect states of Stemphylium. Mycologia 61:1-26.

Singh, P., Bugiani, R., Cavanni, P., Nakajima, H., Kodama, M., Otani, H., and Kohmoto, K. 1999. Purification and biological characterization of host-specific SV-toxins from Stemphylium vesicarium causing brown spot of European pear. Phytopathology 89:947-953.

Singh, P., Park, P., Bugiani, R., Cavanni, P., Nakajiama, H., Kodama, M., Otani, H., and Kohmoto, K. 2000. Effect of host-selective SV-toxin from Stemphylium vesicarium, the cause of brown spot of European pear plants, on ultrastructure of leaf cells. J. Phytopathol. 148:87-93.

Stanke, M., and Morgenstern, B. 2005. AUGUSTUS: A web server for gene prediction in eukaryotes that allows user-defined constraints. Nucleic Acids Res. 33: W465-W467.

Suheri, H., and Price, T. V. 2000. Infection of onion leaves by Alternaria porri and Stemphylium vesicarium and disease development in controlled environments. Plant Pathol. 49:375-382.

Veneault-Fourrey, C., Parisot, D., Gourgues, M., Laugé, R., Lebrun, M. H., and Langin, T. 2005. The tetraspanin gene CIPLS1 is essential for appressoriummediated penetration of the fungal pathogen Colletotrichum lindemuthianum. Fungal Genet. Biol. 42:306-318.

Walton, J. D. 1994. Deconstructing the cell wall. Plant Physiol. 104:1113-1118.

Weber, R. W. 2015. Allergen of the month-Stemphylium. Ann. Allergy Asthma Immunol. 114:A11.

Weber, T., Blin, K., Duddela, S., Krug, D., Kim, H. U., Bruccoleri, R., Lee, S. Y., Fischbach, M. A., Müller, R., Wohlleben, W., Breitling, R., Takano, E., and Medema, M. H. 2015. antiSMASH 3.0-a comprehensive resource for the genome mining of biosynthetic gene clusters. Nucleic Acids Res. 43:W237-W243. 